pology in the University of Naples; Dr. Riccardi, docent of anthropology in the University of Modena; and many others whose works have secured them well-earned titles of honor.

Professor Sergi himself is one of the most industrious of anthropologists. Within the present year I have seen from his pen a learned essay on the "Principles and Methods of Classifying the Human Race," by craniological forms; a "Systematic Catalogue of the Varieties of Man found in Russia;" and a Report on the Anthropological Congress in Moscow in 1892. No doubt under his active guidance the new society will have a prosperous career.

\section{NOTES OF SOME EXPERIMENTS ON THE HOUSE-} FLY.*

BY JOHN B. SMITH, SC. D., RU'TGERS COLLEGE, NEW BRUNSWICK, N. J.

INSECTS, in some circumstances, exhibit a tenacity of life which is extremely surprising. They will stand a great deal of mutilation, apparently without manifesting: pain, and will get along quite comfortably on a minimum allowance of wings and legs

The house-fiy is about as common an insect as we have, and I was led recently to try some experiments with a view to locate, as nearly as might be, the seat of life-or rather the controlling nerve centre, for life exists in each cell-in this insect. A number of flies were captured and decapitated. This process, of course, severed not only the nervous cord, and separated the brain from the rest of the body, but it cut as well the alimentary canal, and the main blood vessel, the Aorta. Flies so treated lived from ten to sixteen hours. They had, of course, lost all sense of direction; but had not lost the use of any of their limbs. When they were touched with the point of a needle they would walk away; but always in a straight line, and without attempting to avoid any obstacle that might have been in the way; if the annoyance was more than a little, they would attempt to fly. As in the former case, they were unable to direct themselves, and as soon as they met with an obstacle would rest quietly until again irritated. So long as they were left undisturbed they remained at rest, or if a pencil was presented to them between the fore legs, they would erawl up for a short distance, and again rest quietly. In such cases it was rather difficult to make them loosen their hold; they would cling tightly, and would not, if they could avoid it, loosen their grasp until something else was presented to them to which they could attach themselves. There seemed to be a realization that something was wrong, and occasionally the front legs would pass over the place where the head ought to be; but there was not at any time what could be considered as a manifestation of pain.

From another set of flies the abdomen was cut. This severed the nervous cord, the heart and the digestive system including in the latter almost all save the cesophagus. These insects lived for from six to ten hours, and for a large portion of the time they were active, flying about and running, and in fact behaving themselves like insects that were in all respects normal. As in the other case there seemed to be no active manifestation of pain. For a short time, say half a hour after the abdomen was severed, the insects were constantly extending and withdrawing the proboscis, evidently realizing that something was wrong, in that connection. At no time was there any interference with the power of motion, either of the legs or wings, and in fact it was impossible to see any difference between their case and those of pcrfectly normal flies, under the same cireumstances and confined with them.

*Read before Section F., at the Madison meeting of the A. A. A. S.
Perhaps a few words of explanation concerning the gross anatomy of the fly may not be entirely out of place in order that my experiments may be better understood. Insects, generally, have only a single blood vessel, extending the full length of the body, and lying just beneath the dorsum, or upper surface. The digestive system occupies a large portion of the abdomen, and the central part of the thorax. The nervous system extends the full length of the body, in the form of a double cord, on which there are at somewhat irregular intervals enlargements or ganglia, and it lies on the floor of the body, just above the under surface. That ganglion which is situated in the head, is called the brain. We have seen that severing the brain from the rest of the body did not kill the insect; the severed head in no case showed any power of motion in any of its parts, no matter what means were taken to excite it. So long as the head was left attached to the body, even if the abdomen had been cut off, all the mouth parts, and the antennæ could be readily excited and made to move. No insect that had been mutilated by cutting off the abdomen could be induced to feed or attempt feeding. Cutting off all that part of the nervous cord that was situated in the abdomen produced no interference with the powers of motion. From another set of specimens both head and abdomen were removed, leaving only the thorax with its appendages; how much life remained in the abdomen it was impossible to say, since it contained no appendages that could be readily stimulated. The head, as already mentioned, soon died; but the thorax alone retained life for more than six hours, and these fragments of insects could be readily made to walk, although rarely could they be induced to make use of the wings. Yet if one were held up by the legs with forceps, the wings would be used in trying to escape, and would buzz as lively as if the insect was in full possession of all faculties.

From a number of other specimens the abdomen and that portion of the thorax containing the hind legs were removed. These specimens lived for from five to six hours. Both fore and middle legs remained perfectly active, and the mouth parts were readily stimulated. The hind legs could not be stimulated even where that portion of the thorax bearing them remained attached to the abdomen.

Another set of specimens was treated as were those last mentioned, except that the head also was removed. Here two-thirds of the thorax, containing two pairs of legs, remained alive quite as long as when the head was attached to it ; the presence or absence of the brain appearing to make no difference. Other specimens were taken and these were cut in two between the first and second pairs of legs. The anterior $\mathrm{p} r t$, containing the head and fore legs, remained alive for from four to five hours, although of course incapable of moving about. It was easy to induce an insect so treated to extend its tongue, and indeed this was done quite frequently by the insect even without stimulation. The legs were passed at intervals over the front of the head and there was no difficulty in exciting them to motion by merely touching with a needle or any similar instrument. That part of the insect containing the middle and hind legs and the abdomen seemed devoid of active life, and it was impossible to induce these structures, or the wings, to move, within a very few moments after the operation. Another set of specimens was treated exactly as those last mentioned save that here the head also was cut off. In this case the fragment of the thorax containing the front legs lived for three hours, while the other portions of the insect were apparently dead a very few minutes after the operation. An insect cut in half through the prothorax died almost immediately, neither portion responding to such stimuli as I employed, more than a very few moments after. 
To test this matter in another way, I captured a number of specimens and with finely pointed scissors cut the heart or dorsal vessel, at the middle of the thorax. These insects lived nearly twenty-four hours, proving that the circulation of blood is not dependent entirely upon the heart, and, in fact, these insects lived as long as others which were not mutilated at all, and were kept in the same dish merely as a check. I could not find that these insects differed in their actions in any way from those that were perfectly normal. Another set of specimens was treated by cutting not only through the heart, but also through the oesophagus where it passed through the prothorax, and thus the alimentary canal was severed. Specimens so treated died somewhat sooner than did the previous lot, although they also lived nearly twelve hours. It was also noticed of these insects that the tongue or proboscis was frequently extended and retracted as in the case of those insects in which the abdomen was removed. Another set of specimens was treated by cutting the nervous cord in the thorax just behind the posterior legs. This resulted in the paralysis of the hind legs, but did not appear to affect either the fore and middle legs or the wing's. Where the cord was cut between the middle and hind legs, exactly the same result was obtained. Cutting the cord between the fore and middle legs, close to the middle legs, however, resulted in the paralysis of everything behind the fore legs, and of the wings as well; although the insect lived for more than six hours afterward, both the head and its appendages and the fore legs responding readily to stimulation. As a result of this crude series of experiments, it would seem that the vital point, or, better, the controlling nerve centre in flies, is located in that large ganglion situated in the prothorax, just above the fore legs, and that so long as this remains intact, the insect retains power of motion and evidences active life. Severing or piercing this ganglion, killed the insest at once.

\section{LETTERS TO THE EDITOR.}

* ${ }^{*}$ Correspondents are requested to be as brief as possible. The writer's name is in all cases required as a proof of good faith.

On request in advance, one hundred copies of the number containing his communication will be furnished free to any correspondent.

The editor will be glad to publish any queries consonant with the character of the journal.

\section{HERBARIUM SPECIMENS.}

IN preparing specimens of the Composite family for the herbarium, it is difficult to press the flower so that the
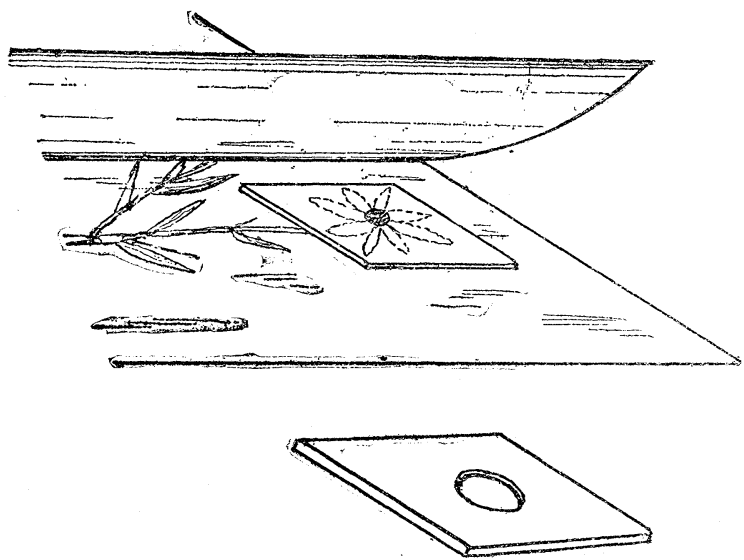

rays will not wilter, owing to the fact that the head keeps the paper from pressing upon the rays. The following device has been used by the writer with much success in preventing this difficulty, and might be useful to students who are collecting autumn flowers.

A small square or disk is cut from blotting paper and a hole is cut in its centre, a little larger than the head of the flower. If, in pressing, this disk be put over the flower, allowing the head to come up through the hole in the centre, the rays can be pressed out flat. The thickness of the disk should vary accordingly as the head is thick or thin. RiChaRD H. RiCH.

Beverly, Mass., Sept. 25, 1893 .

$$
\text { MINNESOTA MOUNDS. }
$$

I READ with considerable surprise Mr. Schneider's article entitled "Notes on Some Minnesota Mounds" in Science of Sept. 1, and I at once felt it to be my painful duty to correct some gross misrepresentations. I happened to be working in the same party with Mr. Schneider when he made the valuable discoveries which he describes and therefore am in a position to criticize his statements.

It is true that we found a number of Indian burialgrounds in the vicinity of Mille Lacs. Most of these were still in use, or had been so until quite recently. In two which I assisted in opening we found some decidedly modern relics, e. g., a U. S. ten cent piece used as a bangle, a glass butter-dish, a rubber comb. and a jack-knife such as any Yankee boy might carry. These graves were arranged in rows and were usually covered with superstructures of wood, which might be compared to dogkennels. We found a few graves rather older than the above, and which were covered with low mounds of earth, but even here there were traces of wooden stakes, which gave evidence of their recent origin. As to the mound at Lake Warren, which Mr. Schneider dug into, I confess that I was not present when it was opened. I have, however, seen the "relics" which were collected from it-in fact $I$ am in a position to see them whenever I wish. Without stopping to question whether the age, sex and stature of the individuals could be accurately determined from the very fragmentary skeletons which he found. I would say that the bones are nearly as well preserved as some which we found in one of the covered graves above described and which $I$ know to have not been huried more than twenty-five years. It is hardly necessary to point out the absurdity of supposing that a hole in which the "roughness of the sides" was still apparent could have been filled for several hundred years.

The specimens of pottery which he describes are merely fragments of baked clay utensils of the roughest sort, just such as all the American Indians manufactured before they obtained iron kettles from the whites.

In fact there is not the least evidence that any of these bones or relics are of any great age or that they belong. to any race older than the Indians which inhabit this district at present. They are of no more value to the archæologist than bones dug from the nearest cemetery.

Francts B. Sumner.

University of Minnesota, Minneapolis, Minn., Sept. 23, I803.

ORIQIN OF GOLD.

I would like to draw attention to a somewhat fallacious deduction which appeared in an interesting little article, "The Origin of Gold," in your issue of Sept. 1st. The author mentions the remarkable fact that, in a part of Southern India, quartz-veins, though traversing both gneiss and belts of rocks, which have been termed the Dharwar, are gold-bearing in the Dharwar only, and are never productive in the gneiss. Mr. Lake then argues: "It is clear, therefore, that the gold cannot have been introauced into the reefs from below, for in that case there would be no difference in that respect between the reefs in the gneiss and the reefs in the Dharwar." 